\title{
Sources and migration of volatile organic compounds in mixed-use buildings
}

\begin{abstract}
We examined concentrations and migration of volatile organic compounds (VOCs) in ten mixed-use buildings in southeast Michigan, USA. In an office and work zone in each building, air exchange rates (AERs) were measured using perfluorocarbon tracers, and over 96 VOC species were measured by GC/MS over a 7-day period. VOCs were then apportioned to sources in offices, work zones, and outdoors using a two-zone mass balance model. AERs averaged $3.9 \mathrm{~h}(0.2-14.2 \mathrm{~h})$ in offices and $1.9 \mathrm{~h}(0.4-3.5 \mathrm{~h})$ in work zones. The dominant VOCs included aromatics, terpenes and alkanes. VOC concentrations were uniform in the smaller spaces, and more variable in some of the very large spaces. Apportionments depended on the VOC and building, but emissions in industrial zones of buildings often migrated to office areas where they frequently accounted for the bulk of VOC concentrations. Outdoor sources accounted for most benzene and carbon tetrachloride, and a small fraction of aromatic and aliphatic compounds. This study shows that pollutant migration can be a significant and not uncommon problem in mixed-use buildings, and it demonstrates the need for better control of emissions and pollutant migration.
\end{abstract}

\section{Jia', S. Batterman², C. Godwin' ${ }^{2}$, S. Charles ${ }^{3}$, J.-Y. Chin ${ }^{2}$}

${ }^{1}$ School of Public Health, University of Memphis, Memphis, TN, USA, ²Department of Environmental Health Sciences, University of Michigan, Ann Arbor, MI, USA, ${ }^{3}$ Jiann-Ping Hsu College of Public Health, Georgia Southern University, Statesboro, GA, USA

Key words: Air exchange rate; Volatile organic compounds; Benzene; Indoor air; Industrial building.

S. Batterman

Department of Environmental Health Sciences

University of Michigan

1420 Washington Heights

Ann Arbor

MI 48109-2029, USA

Tel.: +1 7347632417

Fax: +1 7347638095

e-mail: StuartB@umich.edu

Received for review 11 October 2009. Accepted for publication 27 December 2009.

\section{Practical Implications}

Pollutant exposures in industrial, commercial, and institutional buildings arise from indoor and outdoor sources that can be identified, apportioned, and controlled with knowledge of emission sources and building airflows. We show that multi-tracer techniques are an effective and practical means of determining airflows and exchange rates in large buildings. In examining a set of mixed-use buildings, a substantial fraction of VOC exposures in otherwise relatively 'clean' offices is due to pollutant migration from 'dirty' zones of the building. This indicates the need for corrective actions to minimize exposures of office workers that are unwanted and probably unknown to building managers. These actions should include better control of emissions, isolation or control of air and pollutant flows between building zones, and documentation of the effectiveness of such measures when strong emission sources are present.

\section{Introduction}

Indoor air quality (IAQ) in workplaces, especially offices, is receiving increased attention given the goals of improving the health and productivity of workers (Mitchell et al., 2007), reducing energy consumption, and 'greening' of buildings. Air exchange rates (AERs), mixing within building zones, and airflow rates between building zones are critical parameters for understanding building performance as well as building energy consumption, thermal comfort, and smoke and pollutant migration (Godish and Spengler, 1996).
Good databases exist for AERs in residences (Oie et al., 1998; US EPA, 1997; Weisel et al., 2005), and AERs and other parameters have also been used to predict and understand concentrations and emissions of pollutants in homes, including volatile organic compounds (VOCs), carbonyls, and particulate matter (Batterman et al., 2007; Weisel et al., 2005). Airflows, pollutant levels, and other environment variables also have been measured in schools, offices, libraries, and other large buildings (Godwin and Batterman, 2007; Johnson, 2002; Persily et al., 2006), and there have been many evaluations of specific 'occupational' expo- 


\section{Jia et al.}

sures to workers. However, the literature is much less complete regarding airflows and contaminant levels in mixed-use buildings that contain spaces devoted to several uses, e.g. office, commercial, institutional, and/ or industrial purposes. Such buildings are common, e.g. most large buildings include offices, and they differ from residences in many ways, e.g. mechanical ventilation systems are more sophisticated, building footprints and volumes are larger, and ventilation rates and AERs typically are higher (Eklund and Burrows, 2009). Studies of mixed-use buildings are rare but important as pollutants emitted in one building zone may migrate to another and cause significant exposures (Hansen et al., 1998). However, exposures in such 'distal' zones of mixed-use buildings have been rarely reported. We also note that the relationship between indoor pollutants, ventilation, and exposure has emerged as an occupational research priority (Mendell et al., 2002).

Several factors can complicate the understanding of airflows in large and mixed-use buildings. First, such buildings and especially their larger zones may not be well-mixed, a prerequisite for certain types of AER measurements. Poor mixing also can limit the representativeness of many types of measurements, e.g. pollutant concentrations. Second, certain building zones, e.g. spaces used for warehousing, receiving/ shipping and manufacturing, often utilize a combination of natural and mechanical ventilation, space heaters and fans, all of which may vary seasonally and diurnally. Third, airflow/exchange measurements using tracer gases in multizone buildings may reflect exchange with other building areas, rather than replacement with outside air (ASTM, 2006). Multizone analyses require detailed information, and simultaneous measurements in all building zones can be logistically difficult given the required number and placement of tracer sources and monitors. Finally, deployment of tracer gas emitters, e.g. $\mathrm{SF}_{6}$ and $\mathrm{CO}_{2}$, and the related monitoring equipment can interfere with activities and is costly (Demokritou et al., 2002).
In this study, we examined ten mixed-use commercial and industrial buildings with the objectives of measuring AERs and airflow rates between building zones, measuring VOC concentrations and estimating emissions, and apportioning contributions of the emission sources affecting exposures of office workers. VOCs are extensively used in manufacturing and service industries, and exposures have been associated with a range of respiratory and other health effects (Mitchell et al., 2007). We examined two zones in each building, typically an office area and an industrial/commercial area. Nearly 100 VOCs were measured using adsorbent samplers and GC/MS analysis, and air exchange and migration rates were estimated using the constant injection technique and multiple perfluorocarbon tracers (PFTs).

\section{Methods}

Site description and sampling scheme

Ten commercial or industrial buildings in south-east Michigan were selected to reflect a variety of building types. The selected buildings were used for equipment testing and distribution, manufacturing, museums, offices, auto services, education, and computer servers (Table 1). The buildings represent a convenience sample and, in most cases, permissions and building access were facilitated by contacts of the study team. Measurements were conducted from June, 2005 to December, 2006; some follow-up monitoring was conducted through 2008. Seven buildings were visited once, buildings 1 and 8 were visited twice, and building 6 was visited seven times (seasonally from August, 2006 to November, 2007). Two zones were selected in each building, typically a clerical or office area and an adjacent or nearby work area, e.g. workshop, production center, storage room, library, garage, and computer server room. Building 6 was a special case where both zones were offices. For brevity, the area used for mainly clerical activity is defined as the 'office'

Table 1 Description of the 10 case study buildings and study sites

\begin{tabular}{|c|c|c|}
\hline ID Building description & Office area & Work area \\
\hline 1. Machine testing and distributing company & Machine testing office $\left(33.5 \mathrm{~m}^{2}\right)$ & Loading dock for machine packaging and distribution $\left(31.4 \mathrm{~m}^{2}\right)$ \\
\hline 2. Manufacturer of plastic products & Conference room and office $\left(124.9 \mathrm{~m}^{2}\right)$ & Production of prototype and plastic products $\left(270.1 \mathrm{~m}^{2}\right)$ \\
\hline 3. Moderate-sized plastics plant & $\begin{array}{l}\text { Office and reception area at far south end } \\
\text { of complex }\left(383.3 \mathrm{~m}^{2}\right)\end{array}$ & Production of prototype and plastic products $\left(622.9 \mathrm{~m}^{2}\right)$ \\
\hline 4. Art Museum \& Education Department & Education department office $\left(9.5 \mathrm{~m}^{2}\right)$ & Storage and packing of art materials $\left(206.9 \mathrm{~m}^{2}\right)$ \\
\hline 5. Art Museum & Periodical room $\left(99.2 \mathrm{~m}^{2}\right)$ & Library and book stacks $\left(268.2 \mathrm{~m}^{2}\right)$ \\
\hline 6. University Building & $\begin{array}{l}\text { West office: Faculty office }\left(179.3 \mathrm{~m}^{2}\right) \\
\text { East office: Staff office }\left(486.5 \mathrm{~m}^{2}\right)\end{array}$ & * \\
\hline 7. Tire store and auto service & Reception, showroom, waiting area $\left(143.6 \mathrm{~m}^{2}\right)$ & Auto service $\left(311.8 \mathrm{~m}^{2}\right)$ \\
\hline 8. Computer server building & General office $\left(64.5 \mathrm{~m}^{2}\right)$ & Computer server room $\left(58.4 \mathrm{~m}^{2}\right)$ \\
\hline 9. Computer server building & General office $\left(84.6 \mathrm{~m}^{2}\right)$ & Machine room $\left(78.7 \mathrm{~m}^{2}\right)$ \\
\hline 10. Bus service facility & Office/reception area $\left(133.0 \mathrm{~m}^{2}\right)$ & Bus garage $\left(560.0 \mathrm{~m}^{2}\right)$ \\
\hline
\end{tabular}

*Two office areas were used. 
zone, and the non-office area is referred to as the 'work' space. To help evaluate within-zone variability, VOC samplers were deployed at two locations in each zone. PFT emitters were also deployed at several (typically two) locations in each zone (Table S1). Outdoor VOC samples were collected, and indoor temperature and relative humidity were monitored and recorded continuously using miniature data loggers. A building walkthrough survey was conducted to investigate the building's characteristics, activities, products, and factors potentially related to VOC exposure.

\section{VOC sampling and analysis}

Volatile organic compound and PFT samples were collected over 7 days using tube-type passive samplers mounted on stands and placed in the breathing zone. Each tube was packed with $160 \mathrm{mg}$ of Tenax GR (Scientific Instrument Services, Inc., Ringoes, NJ, USA) and $70 \mathrm{mg}$ of Carbosieve SIII (Supelco, Bellefonte, PA, USA). In the laboratory, samples were analyzed using gas chromatograph/mass spectroscopy and scan mode (GC/MS, Agilent 6890/5973, Palo Alto, CA, USA). Information regarding the samplers, uptake rates, conditioning, storage, transportation, analysis, and other details is provided by Batterman et al. (2006) and Jia et al. (2006). The method detection limits (MDLs) ranged from 0.002 to $0.3 \mu \mathrm{g} / \mathrm{m}^{3}$ depending on the VOC and using the average sampling volume of 3.21 . We report the sum of the 96 target VOCs as $\Sigma$ VOCs. Unless otherwise specified, the median concentration is used to compare results across buildings.

\section{Air exchange and migration rates}

Air exchange rates and airflows were measured using PFTs and the constant injection method. This technique has several advantages in multizone buildings (Batterman et al., 2006). Different tracer gases are released in each zone, and the measured steady-state concentrations are used to determine AERs and interzonal flows using a multi-compartmental mass balance (Sinden, 1978). In each building, two octafluorotoluene (OFT) emitters and two hexafluorobenzene (HFB) emitters were placed in office and work zones, respectively. Additional HFB emitters were deployed in building 10 where the work area was very large. The diffusion-type emitters were held at $40^{\circ} \mathrm{C}$ using electrical heaters to obtain constant emission rates, which averaged $6.0 \pm 4.6$ and $13.8 \pm 5.2 \mathrm{mg} / \mathrm{h}$ for OFT and HFB, respectively (excluding HFB sources in building 10 ), based on the weight loss over the sampling period. Airborne PFT concentrations were measured using the passive VOC samplers described previously. This method is very sensitive, e.g. MDLs were 0.019 and $0.005 \mu \mathrm{g} / \mathrm{m}^{3}$ for $\mathrm{HFB}$ and $\mathrm{OFT}$, respectively. The interior dimensions of the buildings and zones were measured, and the corresponding volumes were calculated. Concentrations of PFTs measured at the several locations within a zone were usually within $20 \%$, and these concentrations were averaged to obtain a zonewide value for use in the AER calculations.

Air exchange rates and flows between building zones were calculated using a two-zone model:

$$
\begin{aligned}
\left|\begin{array}{cc}
\mathrm{Q}_{\mathrm{O}} & -\mathrm{Q}_{\mathrm{O} \rightarrow \mathrm{W}} \\
-\mathrm{Q}_{\mathrm{W} \rightarrow \mathrm{O}} & \mathrm{Q}_{\mathrm{W}}
\end{array}\right| & =\left|\begin{array}{cc}
\mathrm{C}_{\mathrm{OFT}, \mathrm{O}} & \mathrm{C}_{\mathrm{OFT}, \mathrm{W}} \\
\mathrm{C}_{\mathrm{HFB}, \mathrm{O}} & \mathrm{C}_{\mathrm{HFB}, \mathrm{W}}
\end{array}\right|^{-1} \\
& \times\left|\begin{array}{cc}
\mathrm{E}_{\mathrm{OFT}, \mathrm{O}} & 0 \\
0 & \mathrm{E}_{\mathrm{HFB}, \mathrm{W}}
\end{array}\right|
\end{aligned}
$$

where $\mathrm{Q}_{\mathrm{O}}$ and $\mathrm{Q}_{\mathrm{W}}=$ total flows into or out of office and work zones, respectively; $\mathrm{Q}_{\mathrm{W} \rightarrow \mathrm{O}}$ and $\mathrm{Q}_{\mathrm{O} \rightarrow \mathrm{W}}=$ interzonal flows between the two zones $\left(\mathrm{m}^{3} / \mathrm{h}\right) ; \mathrm{C}_{\mathrm{OFT}, \mathrm{O}}$ and $\mathrm{C}_{\mathrm{HFB}, \mathrm{O}}=$ concentrations of OFT and HFB in the office zone $\left(\mathrm{mg} / \mathrm{m}^{3}\right)$; $\mathrm{C}_{\mathrm{OFT}, \mathrm{W}}$ and $\mathrm{C}_{\mathrm{HFB}, \mathrm{W}}=$ tracer concentrations in the work zone $(\mathrm{mg} /$ $\mathrm{m}^{3}$ ); and $\mathrm{E}_{\mathrm{OFT}, \mathrm{O}}$ and $\mathrm{E}_{\mathrm{HFB}, \mathrm{W}}=$ emission rates of OFT and HFB in office and work zones, respectively $(\mathrm{mg} / \mathrm{h})$. This model is described in detail in the Supporting Information. The analysis assumes that outdoor PFT concentrations are negligible (determined to be the case), air in each zone is well-mixed, and concentrations are near steady-state. A short period called the 'mixing time' (Gadgil et al., 2003) is needed for PFT concentrations to reach steady-state conditions after deployment of PFT emitters, which can be calculated as $\mathrm{T}_{\text {mixing }}=3 /$ AER (ASTM, 2006). As discussed later, this does not cause significant errors.

\section{VOC variability and emission rates}

The spatial variability in each zone of VOC and PFT measurements was indicated as the coefficient of variance $(\mathrm{COV})$ of measurements within the zone. In three buildings where repeated sampling visits were made, the temporal variability was calculated as the COV among the spatially averaged measurements.

The emission rates of compound $\mathrm{X}$ in office and work areas, $\mathrm{E}_{\mathrm{O}, \mathrm{X}}$ and $\mathrm{E}_{\mathrm{W}, \mathrm{X}}(\mathrm{mg} / \mathrm{h})$, respectively, were calculated as:

$$
\left|\begin{array}{c}
\mathrm{E}_{\mathrm{O}, \mathrm{X}} \\
\mathrm{E}_{\mathrm{W}, \mathrm{X}}
\end{array}\right|=\left|\begin{array}{cc}
\mathrm{Q}_{\mathrm{O}} & -\mathrm{Q}_{\mathrm{W} \rightarrow \mathrm{O}} \\
-\mathrm{Q}_{\mathrm{O} \rightarrow \mathrm{W}} & \mathrm{Q}_{\mathrm{W}}
\end{array}\right| \times\left|\begin{array}{c}
\Delta \mathrm{C}_{\mathrm{O}, \mathrm{X}} \\
\Delta \mathrm{C}_{\mathrm{W}, \mathrm{X}}
\end{array}\right|
$$

where $\Delta \mathrm{C}_{\mathrm{O}, \mathrm{X}}$ and $\Delta \mathrm{C}_{\mathrm{W}, \mathrm{X}}=$ concentrations of compound $\mathrm{X}$ in office and work zones minus the outdoor concentration $\left(\mathrm{mg} / \mathrm{m}^{3}\right)$, respectively. A source apportionment, giving contributions from the two zones in the building and outdoor sources, was based on the estimated emission rates and mass balance. For each VOC, the percentage contribution from office sources was calculated as $\mathrm{E}_{\mathrm{O}, \mathrm{X}} /\left(\mathrm{Q}_{\mathrm{O}} \mathrm{C}_{\mathrm{O}, \mathrm{X}}\right) \times 100 \%$, and from workplace sources as $\Delta \mathrm{C}_{\mathrm{W}, \mathrm{X}} \mathrm{Q}_{\mathrm{W} \rightarrow \mathrm{O}} /\left(\mathrm{Q}_{\mathrm{O}} \mathrm{C}_{\mathrm{O}, \mathrm{X}}\right) \times$ 


\section{Jia et al.}

$100 \%$. Apportionments for the workplace used analogous calculations: the contribution from workplace sources was $\mathrm{E}_{\mathrm{W}, \mathrm{X}} /\left(\mathrm{Q}_{\mathrm{W}} \mathrm{C}_{\mathrm{W}, \mathrm{X}}\right) \times 100 \%$, and office sources was $\Delta \mathrm{C}_{\mathrm{O}} \mathrm{Q}_{\mathrm{O} \rightarrow \mathrm{W}} /\left(\mathrm{Q}_{\mathrm{W}} \mathrm{C}_{\mathrm{W}, \mathrm{X}}\right) \times 100 \%$. The outdoor concentration was considered as the background level, and the outdoor contribution was calculated as the percentage of the indoor concentration (the derivation of Equations 1 and 2 and source apportionments are detailed in the Supporting Information).

Concentration differences were evaluated used nonparametric Wilcoxon signed rank or Wilcoxon rank sum tests given the possibility of extreme values and the limited sample sizes. SAS 9.1 (SAS Institute Inc., Cary, NC, USA) was used for statistical tests.

\section{Quality assurance $(\mathrm{QA})$}

As part of quality control, one or two blank VOC/PFT samplers were collected at each building, and duplicate samples were collected at one or more of the sampling locations in each building. At building 6 in visits 1 and 3 , blanks showed trace-level concentrations of PFTs $\left(<0.25 \mu \mathrm{g} / \mathrm{m}^{3}\right)$, thus, these samples were corrected by subtracting the average blank levels. The outdoor sample at building 5 visit 1 was ruined by rain water intrusion, and outdoor samples at building 4 visit 1 and building 7 visit 1 were contaminated by high indoor levels; these samples were considered invalid. No other cases of contamination were found. Nearly all samples were collected in duplicate, and most duplicates agreed within 15\%. Duplicate measurements were averaged. QA protocols for the GC/MS analysis included internal standards, QA samples and calibrations (Jia et al., 2006; Peng and Batterman, 2000).

\section{Results}

VOC concentrations

We detected many aromatic, chlorinated, aliphatic, terpenoid, and carbonyl compounds. Table 2 summarizes the most frequently detected compounds, specifically those found in over half of the samples. High concentrations $\left(\Sigma \mathrm{VOCs}>500 \mu \mathrm{g} / \mathrm{m}^{3}\right)$ were

Table 2 Concentrations of VOCs $\left(\mu \mathrm{g} / \mathrm{m}^{3}\right)$ monitored in offices, workplaces, and ambient air

\begin{tabular}{|c|c|c|c|c|c|c|c|c|c|c|c|c|c|c|}
\hline \multirow[b]{2}{*}{ VOCs } & \multirow[b]{2}{*}{$\mathrm{DF}(\%)$} & \multicolumn{4}{|l|}{ Office } & \multicolumn{4}{|c|}{ Workplace } & \multicolumn{4}{|c|}{ Ambient } & \multirow{2}{*}{$\begin{array}{l}0 \rightarrow W \\
P \text {-value }\end{array}$} \\
\hline & & Ave & SD & Med & Max & Ave & SD & Med & Max & Ave & SD & Med & Max & \\
\hline Benzene & 100 & 3.4 & 8.6 & 0.4 & 29.0 & 3.7 & 7.3 & 0.5 & 22.8 & 0.4 & 0.3 & 0.3 & 1.1 & 0.37 \\
\hline Toluene & 100 & 195.2 & 527.7 & 6.0 & 1773.8 & 217.3 & 446.9 & 15.4 & 1383.2 & 6.3 & 14.4 & 1.5 & 54.4 & 0.43 \\
\hline Ethylbenzene & 100 & 3.7 & 4.6 & 1.9 & 13.5 & 5.5 & 5.8 & 2.8 & 15.6 & 0.8 & 1.8 & 0.2 & 7.1 & 0.81 \\
\hline p,m-Xylene & 100 & 14.0 & 18.3 & 7.5 & 55.7 & 20.6 & 22.3 & 12.7 & 57.9 & 2.7 & 6.5 & 0.8 & 25.4 & 1.00 \\
\hline o-Xylene & 100 & 4.1 & 5.6 & 2.4 & 15.9 & 7.0 & 8.4 & 3.0 & 21.6 & 0.7 & 1.5 & 0.3 & 5.9 & 0.40 \\
\hline 1,2,4-Trimethylbenzene & 100 & 8.6 & 16.9 & 1.2 & 57.6 & 14.6 & 22.0 & 1.1 & 60.6 & 0.4 & 0.4 & 0.2 & 1.8 & 0.57 \\
\hline 1,3,5-Trimethylbenzene & 100 & 2.7 & 5.0 & 0.5 & 16.9 & 4.7 & 6.8 & 0.4 & 17.6 & 0.1 & 0.1 & 0.1 & 0.6 & 0.71 \\
\hline 1,2,3-Trimethylbenzene & 100 & 3.0 & 5.8 & 0.5 & 19.6 & 6.0 & 9.6 & 0.4 & 27.8 & 0.1 & 0.2 & 0.1 & 0.7 & 0.40 \\
\hline 4-Ethyl toluene & 100 & 4.4 & 5.6 & 1.0 & 15.7 & 9.9 & 14.6 & 0.7 & 43.8 & 0.3 & 0.3 & 0.2 & 1.4 & 0.39 \\
\hline 2-Ethyl toluene & 95 & 2.6 & 4.8 & 0.5 & 16.4 & 5.1 & 7.7 & 0.4 & 19.7 & 0.1 & 0.2 & 0.1 & 0.6 & 0.46 \\
\hline Isopropylbenzene & 51 & 0.3 & 0.5 & 0.1 & 1.8 & 0.7 & 1.1 & 0.1 & 2.7 & 0.0 & 0.0 & 0.0 & 0.1 & 0.49 \\
\hline n-Propylbenzene & 76 & 1.7 & 3.1 & 0.2 & 10.4 & 3.1 & 4.6 & 0.2 & 11.1 & 0.0 & 0.1 & 0.0 & 0.3 & 0.51 \\
\hline p-Isopropyltoluene & 54 & 0.5 & 0.7 & 0.3 & 2.1 & 0.7 & 1.2 & 0.2 & 3.6 & 0.0 & 0.0 & 0.0 & 0.1 & 0.54 \\
\hline Carbontetrachloride & 81 & 0.2 & 0.1 & 0.2 & 0.4 & 0.2 & 0.2 & 0.2 & 0.4 & 0.3 & 0.2 & 0.3 & 0.8 & 0.49 \\
\hline Tetrachloroethene & 62 & 7.4 & 16.0 & 0.1 & 39.9 & 32.8 & 79.6 & 0.1 & 239.9 & 0.1 & 0.2 & 0.0 & 0.8 & 0.32 \\
\hline Styrene & 76 & 0.6 & 0.7 & 0.3 & 2.4 & 0.7 & 0.7 & 0.4 & 2.5 & 0.0 & 0.0 & 0.0 & 0.1 & 1.00 \\
\hline a-Pinene & 59 & 3.9 & 7.0 & 0.8 & 23.6 & 4.2 & 7.3 & 0.9 & 23.1 & 0.1 & 0.2 & 0.0 & 0.6 & 0.09 \\
\hline d-Limonene & 89 & 5.5 & 5.1 & 3.0 & 14.7 & 5.2 & 4.1 & 5.3 & 12.1 & 0.0 & 0.1 & 0.0 & 0.3 & 0.83 \\
\hline Naphthalene & 95 & 1.9 & 3.4 & 0.5 & 11.6 & 2.2 & 3.2 & 0.9 & 10.2 & 0.1 & 0.1 & 0.1 & 0.5 & 0.32 \\
\hline Phenol & 70 & 6.8 & 12.3 & 0.5 & 32.2 & 7.4 & 12.2 & 1.5 & 33.8 & 0.0 & 0.1 & 0.0 & 0.2 & 0.41 \\
\hline Methyl isobutyl ketone & 51 & 209.6 & 655.7 & 0.4 & 2185.0 & 246.6 & 693.7 & 0.5 & 2095.3 & 1.9 & 6.8 & 0.0 & 25.5 & 0.85 \\
\hline Methyl cyclohexane & 73 & 2.6 & 6.6 & 0.2 & 22.4 & 5.2 & 12.5 & 0.3 & 38.2 & 0.2 & 0.6 & 0.0 & 2.2 & 0.36 \\
\hline n-Heptane & 86 & 9.8 & 20.4 & 2.0 & 69.1 & 21.5 & 38.5 & 1.4 & 106.3 & 1.0 & 3.2 & 0.1 & 11.9 & 0.37 \\
\hline n-Octane & 86 & 2.1 & 2.9 & 0.8 & 9.4 & 3.4 & 3.7 & 1.6 & 10.6 & 0.2 & 0.4 & 0.0 & 1.5 & 0.74 \\
\hline n-Nonane & 70 & 9.4 & 13.4 & 1.3 & 40.8 & 20.4 & 29.3 & 3.4 & 74.7 & 0.3 & 0.8 & 0.0 & 2.5 & 0.55 \\
\hline n-Decane & 81 & 15.6 & 31.8 & 2.8 & 105.8 & 30.7 & 57.2 & 2.4 & 175.1 & 0.3 & 1.0 & 0.0 & 3.9 & 0.35 \\
\hline n-Undecane & 97 & 9.5 & 16.8 & 1.5 & 45.5 & 16.1 & 23.0 & 1.5 & 62.4 & 0.1 & 0.3 & 0.0 & 1.2 & 0.58 \\
\hline n-Dodecane & 78 & 3.6 & 7.2 & 0.3 & 24.5 & 4.0 & 5.3 & 1.1 & 14.9 & 0.0 & 0.0 & 0.0 & 0.0 & 0.30 \\
\hline $\mathrm{n}$-Tridecane & 62 & 1.4 & 1.9 & 0.4 & 5.2 & 1.7 & 2.2 & 0.9 & 6.6 & 0.0 & 0.1 & 0.0 & 0.2 & 0.19 \\
\hline n-Tetradecane & 68 & 1.5 & 1.6 & 1.1 & 4.3 & 1.3 & 1.1 & 0.9 & 3.5 & 0.0 & 0.1 & 0.0 & 0.2 & 0.05 \\
\hline n-Pentadecane & 51 & 1.3 & 1.4 & 1.0 & 3.2 & 1.0 & 0.7 & 1.0 & 2.1 & 0.0 & 0.0 & 0.0 & 0.0 & 0.06 \\
\hline$\Sigma \mathrm{VOCs}$ & 100 & 785.8 & 2001.2 & 72.5 & 6753.7 & 988.3 & 1929.5 & 91.2 & 5992.0 & 20.1 & 34.9 & 4.5 & 124.7 & 0.68 \\
\hline
\end{tabular}

Ave, average; SD, standard deviation; Med, median; Max, maximum; $0 \rightarrow W$-value, $P$-values calculated in Wilcoxon signed rank tests $(n=9)$ comparing office and workplace concentrations; DF, detection frequency of the compound in indoor environments based on all 37 indoor samples. 
encountered in the work zones of four buildings (buildings 2, 3, 7, and 10) and in three of the four corresponding offices (buildings 3, 7, and 10). These work zones contained strong VOC sources, and emitted pollutants migrated to the offices where they also produced high concentrations (contributions are apportioned later). Skewed distributions are shown by several very high concentrations and substantial differences between average and median statistics. Some of the main findings that apply across most of the ten buildings are noted below:

- BTEX (benzene, toluene, ethylbenzene, and xylene), $\alpha$-pinene, d-limonene, and C7-C11 n-alkanes were the predominant VOCs (median concentrations generally $>1.0 \mu \mathrm{g} / \mathrm{m}^{3}$ in both offices and workplaces).

- Concentrations in work zones generally exceeded levels in offices, but differences were not statistically significant $(P>0.05$, Wilcoxon signed rank tests; Table 2). Paired $t$-tests also indicated that differences in office and work zone averages were not statistically significant. This was unsurprising given the large variation of concentrations in both zones across buildings.

- Outdoor concentrations were low (e.g. only toluene had a median concentration above $1.0 \mu \mathrm{g} / \mathrm{m}^{3}$ ) and far below levels in both office and work zones with the exceptions of benzene and carbon tetrachloride. For these two VOCs, indoor and outdoor concentrations were similar, indicating outdoor sources were responsible for indoor levels. Outdoor benzene levels were lower than recent measurements near residences in the same region (median $=0.70$ $1.08 \mu \mathrm{g} / \mathrm{m}^{3}$; Jia et al., 2008).

As mentioned, we measured very high VOC concentrations in four buildings (Table $\mathrm{S} 2$ shows concentrations in each building). Buildings 2 and 3 were manufacturing facilities for plastic and foam medical and athletic equipment. Levels of toluene, methyl isobutyl ketone and 2-butanone in the work zone of building 3, for instance, ranged from 1400 to $2200 \mu \mathrm{g} /$ $\mathrm{m}^{3}$. Phenol and light alkanes, possible indicators for paints, solvents and waxes, were also found at high concentrations. Building 7 was an automobile service/ sales facility. The predominant VOCs at this facility were components of gasoline vapor and engine exhaust, e.g. aromatic and aliphatic compounds. Many of the same aromatics and alkanes were found in building 10 , a service facility for buses, although the VOC composition reflected diesel emissions, e.g. concentrations of aromatic compounds were low relative to the alkanes.

\section{Spatial variation}

Table 3 lists COVs across measurements in different sites in each zone, a measure of the spatial variability, for the PFT tracers and eight VOCs found at relatively high concentrations (medians $>0.5 \mu \mathrm{g} / \mathrm{m}^{3}$ ). Measurement errors for these compounds are expected to be below 15\% (Jia et al., 2006). ASTM (2006) specifies a $10 \%$ criterion for uniformity of concentrations. Here

Table 3 Spatial variation reported as coefficient of variation (\%) for selected volatile organic compounds and tracers hexafluorobenzene and octafluorotoluene

\begin{tabular}{|c|c|c|c|c|c|c|c|c|c|c|c|c|c|c|c|}
\hline Site ID & $1 a$ & $1 b$ & 2 & 3 & 4 & 5 & $6 b-W$ & $6 b-E$ & $6 g-W$ & $6 g-E$ & 7 & $8 a$ & $8 b$ & 9 & 10 \\
\hline \multicolumn{16}{|l|}{ Office Area } \\
\hline Benzene & 5 & 4 & 75 & 17 & 8 & 3 & 38 & 0 & 102 & 16 & 20 & 7 & 5 & 7 & NA \\
\hline Toluene & 4 & 23 & 53 & 39 & 3 & 7 & 15 & 0 & 3 & 5 & 12 & 3 & 30 & 4 & NA \\
\hline p,m-Xylene & 5 & 7 & 29 & 3 & 12 & 0 & 10 & 1 & 4 & 80 & 24 & 4 & 12 & 4 & NA \\
\hline a-Pinene & 6 & 20 & 30 & 6 & 0 & 2 & 4 & 1 & NA & NA & 12 & NA & 2 & NA & NA \\
\hline $\mathrm{d}$-Limonene & 3 & 19 & 60 & 0 & 4 & 11 & 17 & 19 & 53 & 68 & 31 & 5 & 11 & 4 & NA \\
\hline Naphthalene & 7 & 1 & 96 & 6 & 5 & 5 & 9 & 1 & NA & 21 & 23 & 3 & 2 & 5 & NA \\
\hline n-Decane & NA & 26 & 35 & 1 & 4 & 4 & 17 & 2 & 27 & 71 & 20 & 12 & 3 & 5 & NA \\
\hline n-Tetradecane & 8 & 3 & 91 & 3 & NA & 9 & 9 & 5 & NA & NA & 5 & 7 & 23 & 2 & NA \\
\hline Hexafluorobenzene & 6 & 23 & 27 & 10 & 3 & 1 & NA & 58 & NA & 33 & 7 & 20 & 45 & 0 & NA \\
\hline Octafluorotoluene & 2 & 5 & 6 & 3 & 3 & 5 & 12 & NA & 33 & NA & 8 & NA & 34 & NA & NA \\
\hline \multicolumn{16}{|l|}{ Work area } \\
\hline Benzene & 4 & 19 & 53 & 40 & 4 & 2 & NA & NA & NA & NA & 11 & NA & 15 & 58 & 6 \\
\hline Toluene & 5 & 7 & 37 & 26 & 13 & 4 & NA & NA & NA & NA & 22 & NA & 21 & 22 & 5 \\
\hline p,m-Xylene & 5 & 12 & 19 & 17 & 7 & 11 & NA & NA & NA & NA & 51 & NA & 25 & 10 & 7 \\
\hline a-Pinene & 18 & 8 & 28 & 21 & 30 & 4 & NA & NA & NA & NA & 24 & NA & 16 & 13 & NA \\
\hline d-Limonene & 2 & 7 & 50 & 40 & 7 & 12 & NA & NA & NA & NA & 19 & NA & 29 & 8 & 8 \\
\hline Naphthalene & 1 & 24 & 89 & 30 & 9 & 9 & NA & NA & NA & NA & 30 & NA & 36 & 13 & 7 \\
\hline n-Decane & NA & 0 & 24 & 11 & 8 & NA & NA & NA & NA & NA & 19 & NA & 26 & 7 & 8 \\
\hline n-Tetradecane & 9 & 26 & 75 & 31 & NA & 1 & NA & NA & NA & NA & 37 & NA & 29 & 14 & 9 \\
\hline Hexafluorobenzene & 3 & 26 & 8 & 71 & 60 & 10 & NA & NA & NA & NA & 9 & NA & 18 & 15 & 45 \\
\hline Octafluorotoluene & 6 & 0 & 18 & 61 & 77 & 3 & NA & NA & NA & NA & 3 & NA & 21 & 200 & 20 \\
\hline
\end{tabular}




\section{Jia et al.}

we used a $\mathrm{COV}$ of $30 \%$ as a limit for well-mixed conditions, thus accounting for measurement error.

In offices, OFT levels (where this tracer was released) were very uniform (COVs $<12 \%$ except in two visits to building 8 which showed $34 \%$ ). HFB concentrations showed somewhat greater variation, probably due to the low concentrations found. HFB was also released in the east office of building 6. COVs in this office space were larger $(<35 \%$ in 4 visits, and $58 \%$ and $60 \%$ in visits 2 and 4, respectively), probably because the zone was large $\left(486 \mathrm{~m}^{2}\right)$ and only two emitters were deployed. The spatial variation of VOCs largely paralleled that seen for the tracers, except at building 2 where the clerical area was separated into several small rooms. These results show that most of the studied office areas were well-mixed, implying pollutants emitted within the office, as well as those that migrate into the office from the work space and from outdoors, will be found at similar concentrations throughout the space.

Mixing conditions differed among the work zones. HFB levels (where this tracer was released) varied considerably (COVs from 44 to $72 \%$ ) at three of the larger zones tested (buildings 3, 4, and 10). However, VOC concentrations showed less variation (COVs mostly $<20 \%$ ), suggesting that the numbers and/or distribution of HFB emitters deployed were not optimal. In the other buildings, HFB and VOC concentrations across the work zones were generally similar (COVs $<20 \%$ ), however, indicating good mixing. Still, localized sources sometimes produced significant 'hotspots' and greater variations, e.g. toluene and d-limonene had COVs from 53 to $60 \%$ in building 2 , far exceeding the variation seen in the tracers.

Estimates of spatial variability using COVs will depend on the number and placement of monitoring sites. Misleading results can be obtained if a monitoring site is near an emission source, or if measurement errors are large. Our results for the various VOCs and PFTs were generally consistent. Most of the offices had low COVs for both the VOCs and PFTs, showing wellmixed conditions. Mixing conditions varied in workspaces, but even so, most workspaces had COVs below $40 \%$ for most VOCs. These findings support the use of the spatial average concentration in AER and flow determinations. Uncertainties will be greater for poorly mixed spaces.

\section{Temporal variation}

Repeated measurements at several buildings were used to investigate temporal variability. In two visits to building 1, a small machine testing and distributing company, concentrations of several of the predominant compounds in both office and work zones varied considerably, e.g. COVs exceeded $100 \%$ for xylenes, $\alpha$-pinene, and d-limonene. However, AERs in the office zone, a closed and mechanically ventilated space, were stable $(0.4-0.6 \mathrm{~h})$. AERs in the work zone varied from 1.4 to $2.2 \mathrm{~h}$, reflecting opening of a garage door at the loading dock. Building 8 contained mechanically ventilated office and computer server areas. In two visits, concentrations $(\mathrm{COV}<30 \%)$ and AERs (3.2-3.5 h) did not change significantly (the office zone AER in visit 1 could not be determined due to a failure of the OFT measurements). Building 6, a large academic building, was studied over seven seasons, giving an excellent opportunity to examine temporal variation (Figure S1). In the two office areas studied, VOC concentrations showed moderate fluctuations, e.g. COVs $=23-44 \%$ for BTEX compounds, and $\mathrm{COV}=136-173 \%$ for d-limonene, associated with periodic cleaning activities. Compounds at low concentrations $\left(<0.5 \mu \mathrm{g} / \mathrm{m}^{3}\right)$ tended to have greater variation, probably due to measurement error (Jia et al., 2006). AERs varied over a twofold range (1.8-5.9 $\mathrm{h}$ in the east office, $4.1-9.4 \mathrm{~h}$ in the west office).

The results are case-specific, but show interesting differences. First, they suggest that naturally ventilated buildings exhibit greater variation in AERs and VOC concentrations than sealed and mechanically ventilated buildings. Second, VOC concentrations vary more than AERs, which is reasonable given that concentrations reflect changes in AERs as well as variability in source emissions. Third, VOCs associated with intermittent sources show the greatest variability. These conclusions must be tempered given that only three buildings had repeated measurements, but they are consistent with our understanding of the processes involved.

\section{Air exchange rates and airflows}

Air exchange rates, interzonal flows and zone temperatures are listed in Table 4. AERs across the offices averaged $3.9 \mathrm{~h}$ and varied considerably (0.2-14.2 h). The four mechanically ventilated offices in sealed buildings (4, 6, 8, and 9) had high AERs, mostly exceeding $3.0 \mathrm{~h}$, and reflect both outside air and, in most cases, air from other zones in the same building. Offices with openable windows or entry doors and a mixture of natural and mechanical ventilation had low AERs, all below $1 \mathrm{~h}$. Such differences in AERs due to ventilation methods have been noted (Bluyssen et al., 1996). AERs in work spaces averaged $1.9 \mathrm{~h}$ (range 0.4 $3.5 \mathrm{~h}$ ), considerably lower than AERs in most offices. Like the offices, AERs were higher (>3.0 h) in mechanically ventilated work spaces (buildings 4,8 , and 9) and lower (0.4-2.2 h) in spaces with a mixture of natural and mechanical ventilation. Among the offices and workspaces with natural ventilation, we did not find any simple relationships between AERs and temperature or other parameters, possibly because our sample size was small, the temperature gradients were weak, and because the buildings differed in many ways. 
Table 4 Air exchange rates and airflows in offices and workplaces

\begin{tabular}{|c|c|c|c|c|c|c|c|c|c|c|}
\hline \multirow[b]{2}{*}{ Site No. } & \multirow[b]{2}{*}{ Visit } & \multicolumn{2}{|c|}{ Temperature } & \multicolumn{2}{|c|}{ Air exchange rate } & \multicolumn{4}{|l|}{ Inter-zonal flow } & \multirow[b]{2}{*}{ Flow direction } \\
\hline & & Office $\left({ }^{\circ} \mathrm{C}\right)$ & Work $\left({ }^{\circ} \mathrm{C}\right)$ & Office (h) & Work (h) & $W \rightarrow 0\left(\mathrm{~m}^{3} / \mathrm{h}\right)$ & $\%$ of $0(\%)$ & $0 \rightarrow W\left(\mathrm{~m}^{3} / \mathrm{h}\right)$ & $\%$ of $W(\%)$ & \\
\hline 1 & 1 & 23.3 & 23.2 & 0.4 & 1.4 & 28 & 69 & 50 & 21 & $0 \rightarrow W$ \\
\hline 1 & 2 & 20.1 & 19.8 & 0.6 & 2.2 & 42 & 80 & 60 & 16 & $0 \rightarrow W$ \\
\hline 2 & 1 & 23.7 & 24.9 & 0.6 & 0.4 & 132 & 76 & 173 & 22 & $0 \rightarrow W$ \\
\hline 3 & 1 & 24.8 & 27.6 & 0.2 & 0.9 & 87 & 71 & 97 & 4 & $0 \rightarrow W$ \\
\hline 5 & 1 & 22.0 & 25.4 & 0.9 & 2.0 & 174 & 70 & 179 & 6 & $0 \rightarrow W$ \\
\hline 7 & 1 & 21.1 & 19.5 & 0.5 & 1.1 & 73 & 40 & 219 & 12 & $0 \rightarrow W$ \\
\hline 10 & 1 & 21.3 & 24.9 & 1.2 & 0.8 & 46 & 11 & 78 & 2 & $0 \rightarrow W$ \\
\hline 4 & 1 & 27.1 & 22.1 & 14.2 & 3.3 & 52 & 14 & 15 & 1 & $W \rightarrow 0$ \\
\hline 8 & 1 & 24.5 & 22.9 & NA & 3.2 & NA & NA & NA & NA & NA \\
\hline 8 & 2 & 24.4 & 22.5 & 11.7 & 3.5 & 163 & 8 & 87 & 15 & $W \rightarrow 0$ \\
\hline 9 & 1 & 22.6 & 18.7 & NA & 3.5 & NA & NA & NA & NA & NA \\
\hline $6^{*}$ & 1 & 20.0 & 19.3 & 8.4 & NA & 0 & 0 & 0 & 0 & No flow \\
\hline $6^{*}$ & 2 & 22.3 & 22.4 & 9.4 & 3.0 & 0 & 0 & 0 & 0 & No flow \\
\hline $6^{*}$ & 3 & 20.1 & 24.1 & 5.0 & 2.2 & 0 & 0 & 0 & 0 & No flow \\
\hline $6^{*}$ & 4 & 20.8 & 20.2 & 5.2 & 5.9 & 0 & 0 & 0 & 0 & No flow \\
\hline $6^{*}$ & 5 & 17.7 & 21.5 & 4.6 & 4.4 & 0 & 0 & 0 & 0 & No flow \\
\hline $6^{*}$ & 6 & 20.0 & 20.0 & 4.1 & 5.7 & 0 & 0 & 0 & 0 & No flow \\
\hline $6^{*}$ & 7 & 20.3 & 21.8 & 4.4 & 1.8 & 0 & 0 & 0 & 0 & No flow \\
\hline Average & & 22.7 & 22.8 & 3.9 & 1.9 & 76 & 36 & 113 & 10 & \\
\hline SD & & 2.0 & 3.0 & 5.1 & 1.2 & 63 & 33 & 70 & 8 & \\
\hline Minimum & & 20.2 & 18.7 & 0.2 & 0.4 & 0 & 0 & 15 & 1 & \\
\hline Median & & 22.0 & 22.1 & 1.1 & 1.8 & 63 & 27 & 92 & 9 & \\
\hline Maximum & & 27.1 & 27.6 & 14.2 & 3.5 & 174 & 76 & 219 & 22 & \\
\hline
\end{tabular}

$\mathrm{W} \rightarrow 0$, airflow from workplace to office; $0 \rightarrow W$, airflow from office to workplace; \% of 0 , percentage of the total office airflow represented by the flow from the workplace; \% of $W$, percentage of the total workplace airflow represented by the flow from the office; NA, not available.

*The work area at site no. 6 is the east office.

Airflows between work and office zones were detected at each building (excluding building 6 where two offices were studied; Table 4). These flows can occur through doors, passages, other penetrations in the building, the ventilation system, and intake of air exhausted from the building. Workplace-to-office flows represented an average of $36 \pm 33 \%$ of the total exchange in the offices, and offices in buildings $1,2,3$, and 5 received most $(69-80 \%)$ of their air from the connected workplace. This is a significant and disturbing finding as this means pollutants will migrate from the work zone into the office (quantified in the next section which apportions VOCs). The reverse flows also occurred, and work zones received an average of $10 \pm 8 \%$ of their air from offices (in no case more than $23 \%$ ). Generally these 'reverse' flows have little consequence for pollutant exposure given the lack of strong pollutant sources in offices.

We expect but did not characterize seasonal variation, especially in buildings using natural ventilation. In all cases where temperature differences were significant, we found that the predominant flows were from the cooler to the warmer zones. In our summer measurements in buildings using a mixture of natural and mechanical ventilation, air flowed from (cooler) offices to (warmer) workplace zones, which had windows and doors. In winter, we expect workplaces to be colder than offices, which may induce larger workplace-to-office flows that bring work-related air pollu- tants to office spaces. Moreover, concentrations may increase in the work zone in winter, as AERs in naturally ventilated workspaces will decrease as windows and doors are closed. This will further increase pollutant concentrations in office zones.

\section{Emissions of VOCs}

Emission rates varied significantly among the buildings, especially for the predominant compounds (e.g. BTEX, alkanes, and terpenes; Table 5). Workplaces tended to have higher emissions than offices, but differences were not statistically significant (Wilcoxon signed rank tests).

We divided the workplaces into low and high emitter groups. The low group, with emissions of individual VOCs mostly $<5 \mathrm{mg} / \mathrm{h}$ and $\Sigma$ VOCs emissions $<50$ $\mathrm{mg} / \mathrm{h}$, included workspaces in buildings $1,4,5,8$, and 9 (areas for instrument testing, library storage, and servers). The high emission group, which included workspaces in buildings 2, 3, 7, and 10 (plastics manufacturing and auto repair), had $\Sigma$ VOCs emissions from 361 to $15,475 \mathrm{mg} / \mathrm{h}$, and emissions of aromatics, alkanes and d-limonene frequently ranged from 100 to $1000 \mathrm{mg} \mathrm{h}$. Workspaces in buildings 2 and 3 had particularly high emissions of phenol, 2-butanone and methyl isobutyl ketone.

In offices, VOC source strengths were generally weak, mostly below $5 \mathrm{mg} / \mathrm{h}$ for individual VOCs. The 


\section{Jia et al.}

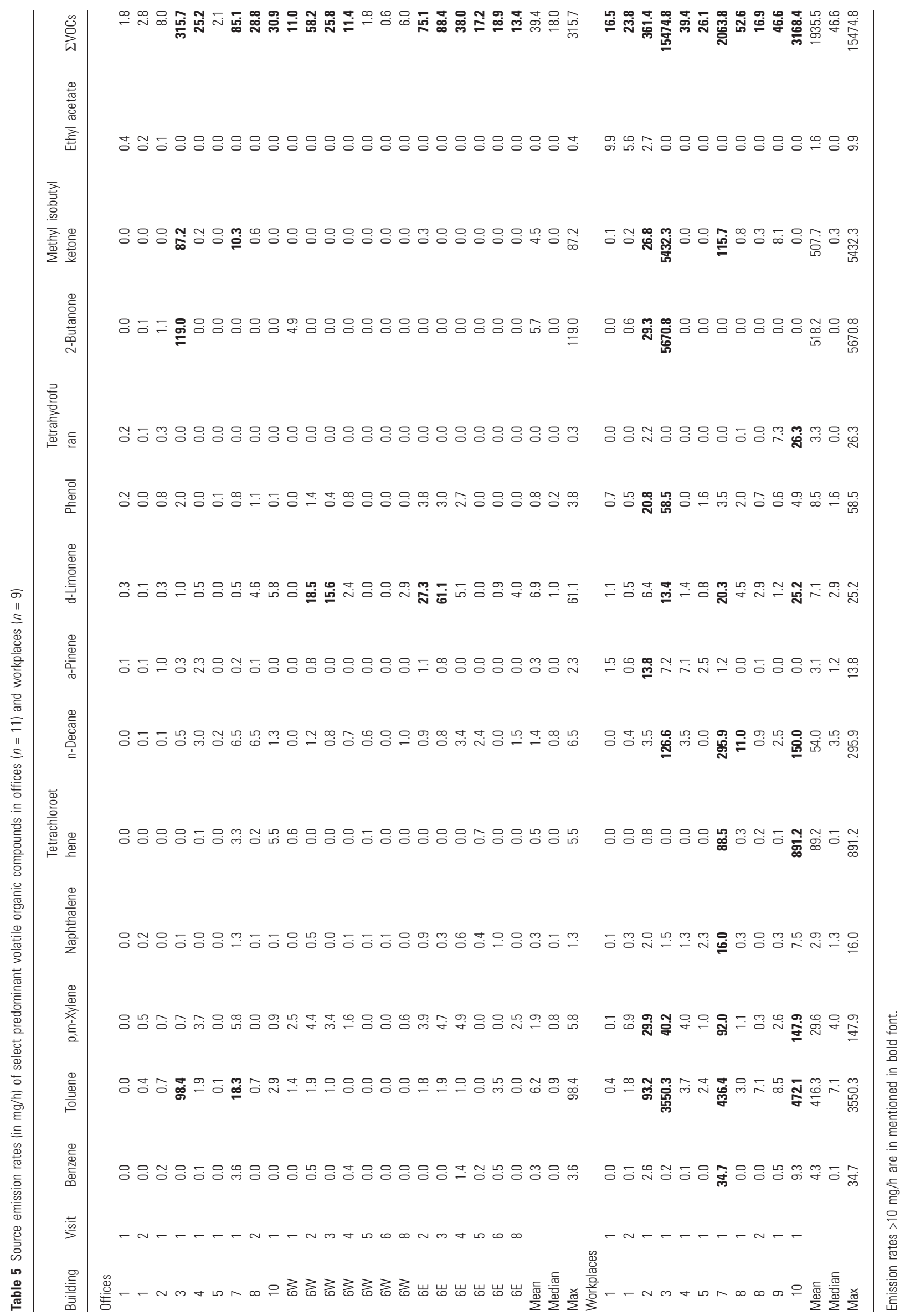


exceptions included three buildings with high emission rates in the workspaces: building 3 , the athletic production facility, showed high emissions of toluene (98 $\mathrm{mg} / \mathrm{h}$ ), 2-butanone (119 mg/h), and methyl isobutyl ketone $(87 \mathrm{mg} / \mathrm{h})$; building 6 , the academic building, showed high emissions of d-limonene (16 and $61 \mathrm{mg} / \mathrm{h}$ in visits 2 and 3 in both offices), a component of many cleaners; and building 7, the tire service store, showed high emissions of toluene $(18 \mathrm{mg} / \mathrm{h})$ and methyl isobutyl ketone $(10 \mathrm{mg} / \mathrm{h})$. The high emissions estimated for the offices in these mixed-use buildings appear related primarily to workplace activities, rather than office or clerical activities. For example, in the tire store, the office contained new tires and wheel rims which might emit VOCs due to off-gassing, polishes, waxes, etc.

To account for building size, emission estimates were expressed on an areal basis, e.g. $\mu \mathrm{g} / \mathrm{h} / \mathrm{m}^{2}$ (Table S3). Some of the variability between buildings is due to building size, but most of the variability resulted from different emission sources in the spaces, especially in the work zones.

\section{VOC apportionments in offices and workspaces}

Volatile organic compounds concentrations to office, workplace, and outdoor air sources were apportioned using PFT-determined airflows and measured concentrations. Apportionments for 17 common VOCs and $\Sigma$ VOCs are displayed in Figure 1 (more statistics are listed in Table S4). For the offices, VOCs were classified into five groups, based on the origin of their sources, as discussed below.

The first group consisted of VOCs emitted from mainly outdoor sources, and included carbon tetrachloride and benzene. Carbon tetrachloride, a stable chemical that is ubiquitous in ambient air, was found at similar levels in offices, workplaces and outdoors. Outdoor sources were estimated to contribute $84 \pm 29 \%$ of the concentrations in offices. Benzene is a component of gasoline as well as a combustion product. Due to its toxicity, benzene has been progressively reduced or eliminated from consumer products and building materials, thus explaining the low emissions estimated for offices and workplaces. We estimated that most benzene $(58 \pm 35 \%)$ in the offices arose from outdoor sources.

The second group of VOCs were mainly or completely due to local (in-office) sources, and included tetrahydrofuran in building 1 , n-nonane and n-decane in building 5, and most of the VOCs in building 4 . Building 4 (art museum) is an unusual mixed-use building in that interzonal flows were small and the workplace was very clean, essentially lacking VOC emission sources.

The third group of VOCs was mainly from workplace sources that migrated into offices. These included n-butyl benzene, cyclohexane, tetrahydrofuran, 2-butanone, methyl isobutyl ketone, and ethyl acetate. Workplace contributions generally exceeded $50 \%$,

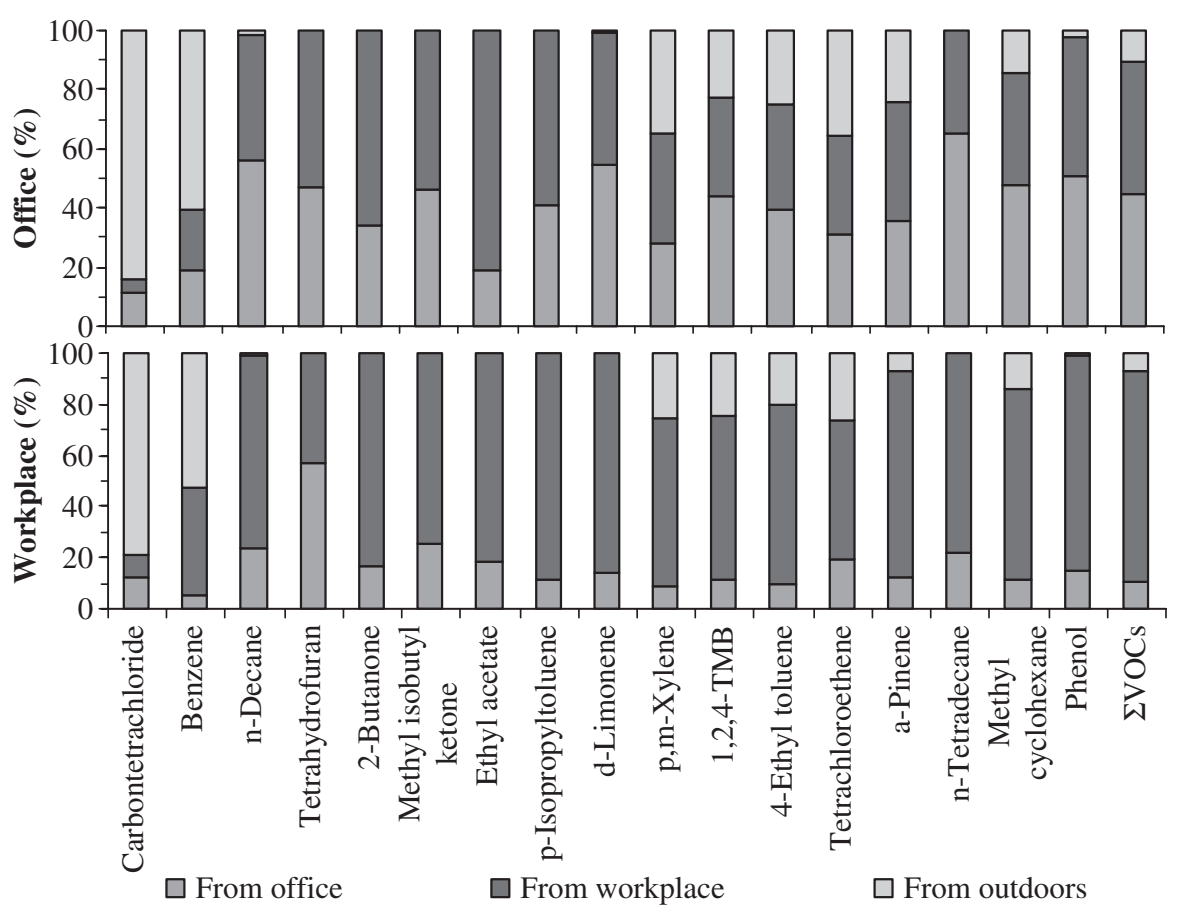

Fig. 1 Average apportionments (\%) of volatile organic compound concentrations in offices and workplaces to outside, office and workplace emission sources ( $n=9$ buildings) 


\section{Jia et al.}

and outdoor sources were not significant. These VOCs are mostly occupation-related, e.g. ethyl acetate is used in glues.

The fourth group of VOCs had both office and workplace sources. These included isopropyl benzene, p-isopropyl toluene, styrene, heavy alkanes, phenol, and d-limonene. These VOCs are used in many products, e.g. building materials, furnishings, paints, cleaning products, and varnishes.

The fifth and last group of VOCs in offices consisted of contributions from office, workplace, and outdoor areas. These included many aromatics, light alkanes, naphthalene, tetrachloroethylene, and $\alpha$-pinene. Outdoor sources of aromatics and light alkanes include gasoline vapors and auto exhaust, naphthalene is a combustion product, tetrachloroethylene is a dry cleaning solvent, and $\alpha$-pinene is a biogenic compound. These VOCs also have indoor sources, e.g. paints, detergents, deodorizers, moth repellents, and furnishings.

In workspaces, the apportionments identified similar sources, but contributions from the local workplace were generally larger, and many VOCs were nearly completely attributable to workplace sources (Figure 1). As seen in the offices, a few VOCs (carbon tetrachloride and benzene) arose mostly from outdoor sources, although workplace sources contributed larger amounts of benzene in buildings 2, 7, and 10 .

The apportionments varied considerably across the buildings (Figure S2 shows apportionments for each building for representative VOCs). Apportionments depend on the VOC sources in the buildings, airflows, differences in interzonal flows (which depend on the building structure, temperature gradient, and ventilation system, e.g. Axley, 2007), and differences in air exchange and ventilation rates. Measurement errors (especially at low concentrations), model errors (especially the appropriateness of a 2-zone fully mixed model), and other sources of uncertainty can also contribute to differences, as discussed below.

\section{Discussion}

Comparisons with previous studies

As noted, IAQ studies in mixed-use buildings are rare. Although office buildings were extensively studied in the 1980s and 1990s, there have been few U.S. studies since 2000. In the 1990s, VOC studies in offices were conducted in 12 buildings in northern California (Daisey et al., 1994), 70 telecommunications offices, data centers and administrative offices across the U.S. (Shields et al., 1996), and 100 'representative' office buildings in the Building Assessment Survey and Evaluation study (Brightman and Moss, 2000). The VOC mixtures and concentrations in offices in the mixed-use buildings were generally consistent with findings in 'smoke-free' buildings in these earlier studies, suggesting that our results are broadly representative of US offices. One important difference is the decrease in benzene concentrations, e.g. our median concentration was only $0.4 \mu \mathrm{g} / \mathrm{m}^{3}$, compared with $3.6 \mu \mathrm{g} / \mathrm{m}^{3}$ in the BASE study, largely a result of decreases in both indoor and outdoor emissions (Hodgson and Levin, 2003; McCarthy et al., 2007), although locational and other factors may also be at play. On the other hand, some of the case study buildings showed higher levels of other common VOCs (e.g. toluene, ethyl benzene, and xylenes), probably a result of migration from 'dirty' work spaces in the mixed-use buildings, which were not emphasized in previous work.

Office buildings also have had extensive study of ventilation conditions over the past three decades, spurred on by problems of sick building syndrome (SBS) among office workers. Turk et al. (1989) reported ventilation rates from 0.3 to $4.2 \mathrm{~h}$ in 38 sealed commercial and institutional buildings (e.g. schools, offices, libraries, and multipurpose buildings). Probably the most representative results are provided by the 100-building BEAM study, which reported a median AER of $0.98 \mathrm{~h}$ and a range from $0-14.9 \mathrm{~h}$ (Persily et al., 2006). AERs in four industrial buildings in Austin, Texas were between 0.6 and $2.8 \mathrm{~h}$ (Fradella and Siegel, 2005). Clearly, AERs can vary substantially among building types, climates, and other factors. Moreover, reported AERs depend on the measurement method (Persily et al., 2006). Overall, we found ranges of AERs in both offices and workplaces that were comparable to literature values.

In contrast to offices, VOC mixtures and concentrations in non-office buildings differ widely, reflecting the building's characteristics, functions, and services. Quite high concentrations of VOCs and aldehydes have been measured in stores and restaurants (Loh et al., 2006). Other case studies have reported VOC levels in a range of buildings, e.g. commercial retail buildings (Eklund et al., 2008), bars (Waring and Siegel, 2007), call centers (Hodgson et al., 2003), a mixed-use university art building (Ryan et al., 2002), and an offset printing facility (Batterman et al., 2002). These and other studies have measured AERs and VOCs, but none have provided quantitative estimates of inter-zone pollutant migration.

\section{Health concerns in mixed-use buildings}

Possibly our most important finding is the prevalence and significance of interzonal airflows and contaminant migration that can greatly elevate pollutant levels in offices and other areas where such exposures are not expected. Unlike 'occupational' or workplace settings, workers in offices are not expecting nor are compensated for pollutant exposures. It is also noteworthy that 
despite the large literature reporting IAQ and health problems in offices (e.g. Seppanen et al., 1999; Wargocki et al., 2002), pollution migration has not been addressed. In general, the current lack of field data appears to preclude an understanding of these issues in multiuse buildings.

Another issue in building studies is the adequacy of the outdoor air supply. Perceived adverse outcomes, such as symptoms associated with SBS are more likely to occur at low ventilation rates, below about 10-25 1/s per person (Seppanen et al., 1999; Wargocki et al., 2002). Most of the study buildings were well ventilated with respect to such criteria, although several of the buildings had low ventilation rates (e.g. buildings 1, 2, 3,5 , and 7 had ventilation rates from approximately 10-70 1/s per person) that might promote SBS-type symptoms. Moreover, ventilation standards for office and other settings where emission sources are not expected do not account for air migration from polluted work zones. If pollutant migration is common and significant in mixed-use buildings, as suggested by this study, then ventilation standards will not be protective.

\section{Study uncertainties}

Concentrations and emission estimates of VOCs in buildings, as well as source apportionment results, vary given the diversity of the buildings, their contents, settings, and occupant activities. This variability is not reducible.

Emission rates and apportionments given by Equations 1 and 2 are subject to many sources of uncertainties. First, PFT and VOC measurements contain errors. Based on duplicate measurements, sampling, and analytical errors were small (mostly $<15 \%$ ). Passive samplers are known to underestimate concentrations due to declining uptake rates, especially for more volatile compounds, longer sampling periods, and higher concentrations (Brown, 1993). For example, using the highest concentration in the study buildings $\left(\right.$ TVOC $\left.=6754 \mu \mathrm{g} / \mathrm{m}^{3}\right)$, the 7-day sampling period, and a model predicting sampler uptake rates (Jia et al., 2007), the maximum bias is $35 \%$ (typical concentrations will produce much smaller biases). This example shows the need to match study conditions and sampling techniques, e.g. intermittent active sampling or grab sampling might be used if very high concentrations are expected. Second, uncertainties can arise due to temporal variation in PFT emission rates and spatial variation in PFT concentrations in each zone. Based on weight measurements, emission rates across the emitters varied by 37 and $76 \%$ (COVs) for HFB and OFT, respectively, largely due to temperature differences (HFB sources were maintained at a constant temperature and thus showed less variation). This did not affect our results as we used emitter-specific rates, however, our evaluation of the spatial distribution of the tracer gases was limited to a few locations. Based on simulations in houses, uncertainties in AERs determined using tracer gases should be on the order of $10 \%$ with good sampler coverage and tracer gas distribution, but uncertainties can rise to $100 \%$ with poor distribution and coverage (Sherman, 1989). We found quite uniform PFT concentrations within most zones, indicating good mixing and distribution of the tracers, but this did not apply for the very largest spaces. Third, uncertainty is introduced by inaccurate building volume estimates (due to errors in zone measurements, unknown voids, openings, etc). Fourth, because PFT sources and samplers were deployed simultaneously, there is a short period of time (mixing time) before PFT concentrations reach steady-state $\left(\mathrm{C}_{\text {steady }}\right)$, thus, the integrated measured concentration $\left(\mathrm{C}_{\mathrm{int}}\right)$ is lower than $\mathrm{C}_{\text {steady. }}$. However, $\mathrm{C}_{\text {int }}$ can be estimated using the derived AER and sampling time (Batterman et al., 2006), and based on the parameters in this study (e.g. AERs from 0.2 to $14.2 \mathrm{~h}$, 7-day sampling period), $\mathrm{C}_{\text {int }}$ should be within $3 \%$ of $\mathrm{C}_{\text {steady }}$, and $\mathrm{T}_{\text {mixing }}$ ranged from 0.2 to $15 \mathrm{~h}$ represented $<9 \%$ of the 7-day sampling period. Fifth, the two-zone mass-balance model, while an improvement over 1-zone models and even simpler indoor/outdoor $(\mathrm{I} / \mathrm{O})$ ratios, still represents a major simplification of large buildings. Although we found that most zones were well mixed, we did not evaluate the vertical distributions of pollutants, which could be problematic (Demokritou et al., 2002; Said, 1997). A larger number of PFT samplers could address some of the variability issues, but this runs into logistical issues. Given appropriate parameters, the use of much more detailed and dynamic multizone models such as CONTAM and COMIS (Lorenzetti, 2002) may be warranted. Sixth, we did not account for possible sinks, e.g. carpets and 'fleecy' materials, and the time variability in flows was averaged out. For this reason, the estimated AER is considered an 'effective' AER (Sherman and Wilson, 1986). Lastly, the method used to estimate airflows and concentrations provides time-averaged results, which may not fully reflect exposures of building occupants, especially if airflows and emission rates in the building are associated with work activity and vary markedly in time. The application of steadystate models, as used in this paper, coupled with such variation can produce systematic biases with result to the conditions that apply during the occupied period (Nazaroff, 2009). As an example, ventilation may decrease at night when workers are not present, resulting in overestimated VOC concentrations, if emission rates are constant through the day, as well as underestimated AERs. Such biases may be partially offset, however, if work-related activities are associated with strong VOC sources. In this case, VOC concentrations might be underestimated if the VOC emission rate at night falls faster than the AER, although the 


\section{Jia et al.}

AER will remain underestimated. Sampling during the occupied period only can avoid such biases and would provide a refined analysis that better reflects exposure and pollution migration.

\section{Conclusion}

We estimated VOC concentrations, airflows, and pollutant migration in office and work zones in ten mixeduse buildings using multiple tracer gases and passive adsorbent sampling. A total of 31 VOCs were frequently detected (in over $50 \%$ of the samples), including BTEX compounds, light alkanes (C7-C11) and terpenes. Extremely high concentrations $(>1000 \mu \mathrm{g} /$ $\mathrm{m}^{3}$ ) of several VOCs, e.g. toluene, methyl isobutyl ketone and 2-butanone, were detected in facilities containing spaces for manufacturing and auto repair. Based on repeated measurements at three buildings, the temporal variation of VOC concentrations was mostly within $40 \%$. Based on measurements at multiple locations in each zone, most of the tested buildings were well-mixed. AERs averaged $3.9 \pm 5.1 \mathrm{~h}$ in offices, and $1.9 \pm 1.2 \mathrm{~h}$ in the work zones. Inter-zonal flows constituted a substantial part $(36 \pm 33 \%)$ of the total ventilation in offices.

Volatile organic compound sources were apportioned to two zones and outdoor air in each building. Outdoor sources were responsible for most benzene and carbon tetrachloride, and significant portions $(10-35 \%)$ of many aromatics and C7-C9 aliphatics. In offices, VOC concentrations arose due to approximately equal contributions from office (local) and workplace (migration) sources. In the workplaces, VOCs were mainly $(>70 \%)$ due to local (workplace) sources. Although the buildings were diverse and the results are subject to a number of uncertainties, the results demonstrate that migration from industrial and commercial spaces into offices is common and contributes a substantial amount of exposure.

To our knowledge, this is the first study to estimate inter-zonal migration of VOCs between offices and workplaces in mixed-use buildings. Additionally, we present information on current levels of a wide range of VOCs in various occupational settings in the U.S., and demonstrate the application of a fairly simple multi-gas tracer method to estimate airflows and pollutant migration. Based on our building sample, pollutant migration appears to be a significant and common problem in mixed-use buildings that contain strong VOC emission sources. This problem will not be solved by increasing AERs in offices as this may increase migration. Better isolation between workplace and office zones and more effective emission controls are needed to resolve such problems.

\section{Acknowledgements}

The authors thank our laboratory and field staff, including Sergei Chernyak, Alisson Stewart, Safia Ziani, Lindsey Lapointe, Tze-Chun Chen, the building managers and support personnel. Portions of this project were supported by the Great Lakes Commission's Great Lakes Air Deposition Program.

\section{Supporting Information}

Additional Supporting Information may be found in the online version of this article:

Fig. S1 Trends of volatile organic compound concentrations and air exchange rates over seven visits in two offices in building 6 .

Fig. S2 Apportionments of volatile organic compounds concentrations in offices $(n=11)$ and workplaces to outside, office and workplace emission source $(n=9)$.

Table S1 Descriptions of the ten case study buildings Table S2 Concentrations of volatile organic compounds $\left(\mu \mathrm{g} / \mathrm{m}^{3}\right)$ monitored in offices and workplaces by building.

Table S3 Emission factors (in $\mu \mathrm{g} / \mathrm{h} / \mathrm{m}^{2}$ ) of predominant volatile organic compounds in offices and workplaces.

Table S4 Apportionments of volatile organic compound concentrations in offices and workplaces to outside, office and workplace emission sources.

Please note: Wiley-Blackwell are not responsible for the content or functionality of any supporting materials supplied by the authors. Any queries (other than missing material) should be directed to the corresponding author for the article.

\section{References}

ASTM (2006) Standard Test Method for Determining Air Change in a Single Zone by Means of a Tracer Gas Dilution, West Conshohocken, PA, American Society for Testing and Materials International. ASTM Standard E741.

Axley, J. (2007) Multizone airflow modeling in buildings: history and theory, HVAC\&R Res., 13, 907-928.
Batterman, S., Metts, T., Kalliokoski, P. and Barnett, E. (2002) Low-flow active and passive sampling of VOCs using thermal desorption tubes: theory and application at an offset printing facility, J. Environ. Monit., 4, 361-370.

Batterman, S., Jia, C., Hatzivasilis, G. and Godwin, C. (2006) Simultaneous measurement of ventilation using tracer gas techniques and VOC concentrations in homes, garages and vehicles, J. Environ. Monit., 8, 249-256.

Batterman, S., Jia, C. and Hatzivasilis, G. (2007) Migration of volatile organic compounds from attached garages to residences: a major exposure source, Environ. Res., 104, 224-240. 
Bluyssen, P.M., Fernandes, E.D., Groes, L., Clausen, G., Fanger, P.O., Valbjorn, O., Bernhard, C.A. and Roulet, C.A. (1996) European indoor air quality audit project in 56 office buildings, Indoor Air, 6, 221238.

Brightman, H.S. and Moss, N. (2000) Sick building syndrome studies and the compilation of normative and comparative values. In: Spengler, J., Samet, J.M. and McCarthy, J.F. (eds) Indoor Air Quality Handbook, New York, McGraw-Hill, 3.1-3.32.

Brown, R.H. (1993) The use of diffusive samplers for monitoring of ambient air, Pure Appl. Chem., 65, 1859-1874.

Daisey, J.M., Hodgson, A.T., Fisk, W.J., Mendell, M.J. and Tenbrinke, J. (1994) Volatile organic-compounds in 12 California office buildings - classes, concentrations and sources, Atmos. Environ., 28 , 3557-3562.

Demokritou, P., Yang, C.X., Chen, Q.Y. and Spengler, J.D. (2002) An experimental method for contaminant dispersal characterization in large industrial buildings for indoor air quality (IAQ) applications, Build. Environ., 37, 305-312.

Eklund, B. and Burrows, D. (2009) Prediction of Indoor air quality from soil-gas data at industrial buildings, Ground Water Monit. Remediat., 29, 118-125.

Eklund, B.M., Burkes, S., Morris, P. and Mosconi, L. (2008) Spatial and temporal variability in VOC levels within a commercial retail building, Indoor Air, 18, 365-374.

Fradella, J. and Siegel, J.A. (2005) An evaluation of shelter-in-place strategies in four industrial buildings. In: Proceedings of Indoor Air 2005, Beijing, China, the 10th International Conference on Indoor Air Quality and Climate, 3360-3364.

Gadgil, A.J., Lobscheid, C., Abadie, M.O. and Finlayson, E.U. (2003) Indoor pollutant mixing time in an isothermal closed room: an investigation using CFD, Atmos. Environ., 37, 5577-5586.

Godish, T. and Spengler, J.D. (1996) Relationships between ventilation and indoor air quality: a review, Indoor Air, 6, 135-145.

Godwin, C. and Batterman, S. (2007) Indoor air quality in Michigan schools, Indoor Air, 17, 109-121.

Hansen, H., De Rosa, C.T., Pohl, H., Fay, M. and Mumtaz, M.M. (1998) Public health challenges posed by chemical mixtures, Environ. Health Perspect., 106, 1271-1280.

Hodgson, A.T. and Levin, H. (2003) Volatile Organic Compounds in Indoor Air: A Review of Concentrations Measured in North America Since 1990, LBNL-51715, Berkeley, CA, USA, Lawrence Berkeley National Laboratory.

Hodgson, A.T., Faulkner, D., Sullivan, D.P., DiBartolomeo, D.L., Russell, M.L. and Fisk, W.J. (2003) Effect of outside air ventilation rate on volatile organic compound concentrations in a call center, Atmos. Environ., 37, 5517-5527.

Jia, C., Batterman, S. and Chernyak, S. (2006) Development and comparison of methods using MS scan and selective ion monitoring modes for a wide range of airborne VOCs, J. Environ. Monit., 8, 1029-1042.

Jia, C., Batterman, S. and Godwin, C. (2007) Continuous, intermittent and passive sampling of airborne VOCs, J. Environ. Monit., 9, 1220-1230.

Jia, C., Batterman, S. and Godwin, C. (2008) VOCs in industrial, urban and suburban neighborhoods. Part 1: Indoor and outdoor concentrations, variation, and risk drivers, Atmos. Environ., 42, 2083-2100.

Johnson, T. (2002). A Guide to Selected Algorithms, Distributions, and Databases Used in Exposure Models Developed by the Office of Air Quality Planning and Standards, US EPA Grant No. CR827033. Available at: http://www. epa.gov/ttn/fera/human_data.html, accessed November 21, 2008.

Loh, M.M., Houseman, E.A., Gray, G.M., Levy, J.I., Spengler, J.D. and Bennett, D.H. (2006) Measured concentrations of VOCs in several non-residential microenvironments in the United States, Environ. Sci. Technol., 40, 6903-6911.

Lorenzetti, D.M. (2002) Assessing multizone airflow simulation software. Proceedings of the 9th International Conference on Indoor Air Quality and Climate. Indoor Air 2002, v1, 267-271.

McCarthy, M.C., Hafner, H.R., Chinkin, L.R. and Charrier, J.G. (2007) Temporal variability of selected air toxics in the United States, Atmos. Environ., 41, 71807194.

Mendell, M.J., Fisk, W.J., Kreiss, K., Levin, H., Alexander, D., Cain, W.S., Girman, J.R., Hines, C.J., Jensen, P.A., Milton, D.K., Rexroat, L.P. and Wallingford K.M. (2002) Improving the health of workers in indoor environments: priority research needs for a national occupational research agenda, Am. J. Public Health, 92, 1430-1440.

Mitchell, C.S., Zhang, J.F.J., Sigsgaard, T., Jantunen, M., Lioy, P.J., Samson, R. and Karol, M.H. (2007) Current state of the science: health effects and indoor environmental quality, Environ. Health Perspect., 115, 958-964.

Nazaroff, W.W. (2009) What does "average" mean for time-varying air-exchange rates?, In: Proceedings of Healthy Buildings 2009, Syracuse, NY, USA. Paper 369.

Oie, L., Stymne, H., Boman, C.-A. and Hellstrand, V. (1998) The ventilation rate of 344 Oslo residences, Indoor Air, 8 , 190-196.

Peng, C. and Batterman, S. (2000) Performance evaluation of a sorbent tube sampling method using short path ther- mal desorption for volatile organic compounds, J. Environ. Monit., 2, 313-324.

Persily, A.K., Gorfain, J. and Brunner, G. (2006) Survey of ventilation rates in office buildings, Build. Res. Inform., 34, 459466.

Ryan, T.J., Hart, E.M. and Kappler, L.L. (2002) VOC exposures in a mixed-use university art building, AIHA J., 63, 703-708.

Said, M.N.A. (1997) Measurements of air change rates and air flow patterns in large single-cell buildings, Energy Build., 26, 175-182.

Seppanen, O.A., Fisk, W.J. and Mendell, M.J. (1999) Association of ventilation rates and $\mathrm{CO}_{2}$ concentrations with health and other responses in commercial and institutional buildings, Indoor Air, 9, 226-252.

Sherman, M.H. (1989) Analysis of errors associated with passive ventilation measurement techniques, Build. Environ., 24, 131-139.

Sherman, M.H. and Wilson, D.J. (1986) Relating actual and effective ventilation in determining indoor air-quality, Build. Environ., 21, 135-144.

Shields, H.C., Fleischer, D.M. and Weschler, C.J. (1996) Comparisons among VOCs measured in three types of US commercial buildings with different occupant densities, Indoor Air, 6, 2-17.

Sinden, F.W. (1978) Multi-chamber theory of air infiltration, Build. Environ., 13, 21-28.

Turk, B.H., Grirnsrud, D.T., Brown, J.T., Geisling-Sobotka, K.L., Harrison, J. and Prill, R.J. (1989) Commercial building ventilation rates and particle concentrations, ASHRAE Trans., 95, 422-433.

US EPA (1997) Exposure Factor Handbook, Washington, DC, US Environmental Protection Agency. EPA/600/P-95/002F a-c.

Wargocki, P., Sundell, J., Bischof, W., Brundrett, G., Fanger, P.O., Gyntelberg, F., Hanssen, S.O., Harrison, P., Pickering, A., Seppanen, O. and Wouters P. (2002) Ventilation and health in nonindustrial indoor environments: report from a European Multidisciplinary Scientific Consensus Meeting (EUROVEN), Indoor Air, 12, 113-128.

Waring, M.S. and Siegel, J.A. (2007) An evaluation of the indoor air quality in bars before and after a smoking ban in Austin, Texas, J. Expo. Sci. Environ. Epidemiol., 17, 260-268.

Weisel, C.P., Zhang, J., Turpin, B.J., Morandi, M.T., Colome, S., Stock, T.H. and Spektor, D.M. (2005) Relationships of Indoor, Outdoor, and Personal Air (RIOPA): Part I. Collection Methods and Descriptive Analyses, Boston, MA, Health Effects Institute, and National Urban Air Toxics Research Center, Houston, TX, Available at: http:// pubs.healtheffects.org/view.php?id $=31$, accessed November 21, 2008. 